\title{
Saúde e meio ambiente nos currículos dos cursos de graduação em comunicação social no Brasil
}

\author{
Health and environment in the curriculums of social communication \\ undergraduate degree in Brazil
}

\section{Salud y medio ambiente en los curriculos de la licenciatura en comunicación social en Brasil}

\author{
Agatha Franco | franco.agatha@gmail.com \\ Fundação Oswaldo Cruz, Instituto de Comunicação e Informação Científica e Tecnológica em Saúde, Programa de \\ Pós-Graduação em Informação e Comunicação em Saúde (PPGICS). Rio de Janeiro, Brasil.
}

Raíza Tourinho dos Reis Silva Lima | raizatourinho@yahoo.com.br

Fundação Oswaldo Cruz, Instituto de Comunicação e Informação Científica e Tecnológica em Saúde, Programa de Pós-Graduação em Informação e Comunicação em Saúde (PPGICS). Rio de Janeiro, Brasil.

Tatiana Clébicar | tatiana.clebicar@gmail.com

Fundação Oswaldo Cruz, Instituto de Comunicação e Informação Científica e Tecnológica em Saúde, Programa de Pós-Graduação em Informação e Comunicação em Saúde (PPGICS). Rio de Janeiro, Brasil.

Adriana Cavalcanti de Aguiar | adriana.aguiar@icict.fiocruz.br

Fundação Oswaldo Cruz, Instituto de Comunicação e Informação Científica e Tecnológica em Saúde, Programa de Pós-Graduação em Informação e Comunicação em Saúde (PPGICS). Rio de Janeiro, Brasil.

\section{Resumo}

Acreditamos que a insuficiência de formação em temas de saúde e meio ambiente resulta em coberturas jornalísticas superficiais e em discussões limitadas por parte das assessorias de comunicação ou dos profissionais encarregados das relações públicas no mundo corporativo e no terceiro setor. No caso da graduação em comunicação social no Brasil, uma discussão em torno dos currículos parece ser especialmente oportuna, pois integrar comunicação, saúde e meio ambiente implica em superar a lógica disciplinar na formação superior. Este artigo descreve o cenário da oferta de cursos sobre esses temas pelas instituições de ensino superior brasileiras, utilizando a análise de conteúdo para inferir temáticas recorrentes a partir de categorias presentes nas ementas disponíveis na internet. Os resultados não identificaram a abordagem do trinômio comunicação-saúde-meio ambiente de modo integrado nas graduações em comunicação, indicando, porém, associações entre dois dos temas, especialmente saúde e meio ambiente.

Palavras-chave: comunicação; saúde; meio ambiente; currículo; educação superior. 


\begin{abstract}
We think that insufficient training in health and environment issues results in superficial news coverage and limited discussions by communication consultants or by respon- sible people for public relations of the corporate world and the third sector organizations. In regard to social communication undergraduate degree, a debate about curriculums could be especially timely insofar as to integrate communication, health and the environment there is a need for overcoming the disciplinary logic in higher education. This paper describes the scenario of the courses on these subjects offered by Brazilian higher education institutions, using the content analysis to infer recurring themes from existent categories found in available registers at the internet. Although no result have revealed an approach of trinomial communication-health-environment in an integrated manner in the social communication undergraduate degree in Brazil, the analysis presents several associations of two of those subjects, particularly health and environment.
\end{abstract}

Keywords: communication; health; environment; curriculum; higher education.

\title{
Resumen
}

Creemos que la insuficiente formación en temas de salud y medio ambiente resulta en una cobertura periodística sin profundidad y en discusiones limitadas entre los asesores de comunicación o los relacionistas públicos del mundo empresarial y del tercer sector. En el caso de los estudios de graduación en comunicación social, una discusión de los currículos parece especialmente oportuna puesto que la integración de la comunicación, la salud y el medio ambiente presupone la superación de la lógica disciplinar en la educación superior. Este artículo describe el escenario de la oferta de cursos acerca de aquellos temas por las instituciones brasileñas de enseñanza superior, adoptando el análisis de contenido para inferir temas recurrentes de las categorías presentes en los registros disponibles en internet. Aunque los resultados no hayan identificado el trinomio comunicación-salud-medio ambiente tratado de manera integrada en los cursos de graduación en comunicación social en Brasil, pero se ha observado asociaciones entre dos de los temas, en especial la salud y el medio ambiente.

Palabras clave: comunicación; salud; medio ambiente; curriculum; enseñanza universitaria.

Contribuição dos autores: Agatha Franco, Raíza Tourinho dos Reis Silva Lima e Tatiana Clébicar participaram de todas as etapas de produção do artigo. Adriana Cavalcanti de Aguiar contribuiu no desenho do estudo e na revisão crítica do texto e do conteúdo intelectual.

Declaração de conflito de interesses: não há conflito de interesses.

Fontes de financiamento: Coordenação de Aperfeiçoamento de Pessoal de Nível Superior (CAPES) e Fundação de Amparo à Pesquisa do Estado do Rio de Janeiro (Faperj)

Considerações éticas: Nada a declarar.

Histórico do artigo: Submetido: 13.jun.2016 | Aceito: 15.set.2016 | Publicado: 23.dez.2016.

Licença CC BY-NC atribuição não comercial. Com essa licença é permitido acessar, baixar (download), copiar, imprimir, compartilhar, reutilizar e distribuir os artigos, desde que para uso não comercial e com a citação da fonte, conferindo os devidos créditos de autoria e menção à Reciis. Nesses casos, nenhuma permissão é necessária por parte dos autores ou dos editores. 


\section{Introdução}

Debates em torno da relação entre saúde e meio ambiente atravessam diferentes disciplinas do conhecimento. Sua relevância pode ser mensurada pelas cifras destinadas a financiamentos para pesquisas na área e, consequentemente, pela vasta produção acadêmica resultante desses trabalhos ${ }^{1}$. Esses dois indicadores não dão conta, no entanto, da importância atribuída a esses temas na vida social. Questões de saúde/doença e meio ambiente pautam conversas de bar, reuniões de condomínio e a produção dos meios de comunicação. São dois tópicos cuja importância é consenso². Poucos esperariam conhecimento técnico sofisticado nas conversas informais. Por outro lado, é desejável que aqueles que tratam de tais assuntos (e de suas múltiplas variáveis) profissionalmente contem com uma formação que lhes permita dialogar de maneira acurada com o seu público. Isso vale para profissionais dos mais variados setores, incluindo os de comunicação.

No caso desses profissionais, poucos são os que tiveram oportunidades de aprofundamento em temas de saúde e meio ambiente ao cursarem a graduação. Em se tratando de temas complexos e controversos, a falta de formação mínima sobre eles resulta em pautas e coberturas pouco aprofundadas a seu respeito, bem como em uma discussão limitada por parte das assessorias de comunicação ou dos profissionais encarregados das relações públicas no mundo corporativo ou no terceiro setor. Não raro, a atuação desses profissionais nos diversos ramos da comunicação é incapaz de refletir a complexidade e de fazer as conexões entre as temáticas saúde e meio ambiente, o que nos leva a discutir os currículos de instituições de ensino superior (IES).

A presente reflexão decorre do encontro das autoras (três então mestrandas e uma docente) no Programa de Pós-Graduação em Comunicação e Informação em Saúde (PPGICS), do Instituto de Comunicação e Informação Científica e Tecnológica (Icict) da Fundação Oswaldo Cruz (Ministério da Saúde). Objetiva descrever o cenário das disciplinas ofertadas por IES brasileiras, utilizando a análise de conteúdo para inferir temáticas recorrentes a partir de categorias presentes nas ementas disponíveis na internet.

\section{Alguns dilemas da educação superior}

Os debates em torno dos currículos do ensino superior ecoam na obra de diferentes autores do campo da educação, abordando os desafios da universidade contemporânea e a sua crise. Para o pedagogo espanhol Miguel Zabalza ${ }^{3}$, essa crise reflete as muitas expectativas em relação à universidade, que teria quatro compromissos principais para com a sociedade:

De modo sucinto, está se dizendo às universidades que não se contentem em apenas transmitir a ciência, mas que criem (isto é, elas devem combinar a docência e a pesquisa); que deem um sentido prático e profissionalizante para a formação que oferecem aos estudantes; que façam tudo isso sem se fechar em si mesmas; façam-no em contato com o meio social, econômico e profissional com cuja melhora devem colaborar.

Para cumprir esses compromissos, a universidade precisa examinar seus processos internos e suas relações externas. Os estudos do currículo estabelecem pontes nesses dois sentidos. Lopes ${ }^{4}$ observa que a educação superior precisa dar conta da formação de trabalhadores (com conhecimentos e habilidades específicas) que tenham capacidade de inovação. Critica os currículos disciplinares pouco atentos à relevância social dos conteúdos e estreitamente ligados aos interesses de mercado, e analisa a integração curricular, reconhecendo que os currículos ditos 'integrados' não estão imunes à cooptação por essas mesmas forças.

Integrar comunicação, saúde e meio ambiente implica superar a lógica disciplinar isolada. No caso da graduação em comunicação social, uma discussão em torno dos currículos é especialmente oportuna, 
especialmente a partir de 2009, quando a exigência de diploma para o exercício do jornalismo foi extinta pelo Supremo Tribunal Federal e passou a tramitar, no Congresso Nacional, a Proposta de Emenda Constitucional (PEC) 386/2009, com o objetivo de restabelecer sua obrigatoriedade, enquanto as IES debatem a relevância de seus currículos ${ }^{5}$. Independentemente do desfecho da tramitação, é defensável a ampliação de conteúdos de saúde e de meio ambiente no currículo de futuros comunicadores - e isso deve ir além da formação de jornalistas.

As diretrizes curriculares nacionais (DCN) para os cursos de comunicação reforçam a necessidade de conteúdos que associem teoria e prática. Publicadas em 2001, as DCN buscaram flexibilizar a estruturação dos cursos, de modo a se adaptarem aos diferentes contextos em que estão inseridos, estimulando projetos pedagógicos inovadores. O egresso de cursos de comunicação, de acordo com essas diretrizes, deve ter "habilidade em refletir a variedade e mutabilidade de demandas sociais e profissionais na área, adequandose à complexidade e velocidade do mundo contemporâneo" ${ }^{\circ}$. Em relação aos conteúdos, as DCN demandam "conteúdos teórico-conceituais; conteúdos analíticos e informativos sobre a atualidade; conteúdos de linguagens, técnicas e tecnologias midiáticas, conteúdos ético-políticos”. Assim, compreendemos que a inclusão dos temas de saúde e ambiente na graduação em comunicação social atenderia à expectativa de preparar seus egressos para lidar com as questões complexas de nosso tempo. Além disso, em 2013, as habilitações de jornalismo e relações públicas passaram a contar também com DCNs específicas, que deveriam ser implementadas até o ano de 2016 - em curso, portanto, durante o levantamento que subsidiou este estudo. Em ambos os casos, os eixos de formação destacam especificamente a necessidade de a formação pedagógica incluir assuntos referentes à sustentabilidade ambiental.

Abordagens integradas facilitam a elaboração da diversidade e complexidade dos problemas que se apresentam na atualidade: "Do ponto de vista da investigação das questões ambientais e da saúde, a abordagem interdisciplinar é recomendada para a análise de problemas complexos com múltiplas e irredutíveis dimensões"7. Ocorre que, analisando as estruturas curriculares dos cursos, Bernardo e Leão ${ }^{8}$ observaram quanto "as matrizes curriculares de jornalismo ainda estão 'presas' à estrutura do Currículo Mínimo", que orientava currículos segundo a legislação agora superada.

\section{Relações entre saúde e meio ambiente}

Apesar de as relações entre saúde e ambiente serem tecidas desde a Antiguidade 7 , é na década de 1970 que a correlação entre esses temas ganha visibilidade. Há pouco mais de 40 anos, a alarmante repercussão das influências da poluição sobre a qualidade de vida e seus impactos sobre a saúde da população despertaram a atenção da opinião pública, especialmente nos países industrializados. O cenário de grandes incertezas provocou medo frente aos potenciais riscos ambientais e para a saúde humana, mobilizando as nações a discutirem propostas de desenvolvimento que considerassem, além dos fatores científicos, tecnológicos e econômicos, a variável ambiental ${ }^{9-11}$. Foi nesse contexto que o mundo foi convocado a discutir as questões ambientais e os seus potenciais riscos para as inúmeras esferas da vida humana. O marco desse debate foi a Conferência de Estocolmo, realizada em 1972 na Suécia, e que estabeleceu algumas das bases teóricoconceituais da discussão sobre desenvolvimento, ambiente e sociedade.

Dentre os desdobramentos das discussões em Estocolmo, no final dos anos 1970, emergiram abordagens integradas sobre saúde e ambiente "quando tanto ambientalistas quanto sanitaristas, tanto investigadores quanto gestores, começaram a perceber a necessidade de articular mais suas teorias e suas ações com a ideia da qualidade de vida de populações concretas" ${ }^{\prime 2}$. Surgia o campo da saúde ambiental no Brasil, concebendo-a como resultante da interação de aspectos biológicos e sociais, com reflexos nas políticas públicas $^{13}$. Essa abordagem integrada vem sendo incorporada progressivamente à agenda política mundial 
e convertida em marcos legislativos. No Brasil, destacamos a VIII Conferência Nacional de Saúde em 1986, que ressaltou as relações entre saúde e saneamento básico ${ }^{12,14}$.

Por outro lado, atores institucionais dos campos da saúde e do meio ambiente enfatizam a necessidade de que os profissionais de comunicação sejam convidados a ser parceiros, não apenas no sentido da divulgação das agendas desses campos, mas como mediadores entre a sociedade civil e as entidades políticas e de pesquisa $^{14-17}$. Esse convite parece ter sido aceito ao menos parcialmente: temas de saúde vêm conquistando espaço cada vez maior nos veículos de comunicação no Brasil e em outros países ${ }^{18-19}$. Apenas a título de exemplo, recorremos a uma pesquisa de opinião realizada com leitores de um dos mais importantes jornais do país. O tema saúde é referido como o que mais interessa a esse público: $83 \%$ afirmam ser o assunto que leem com mais frequência e $19 \%$ apontam-no como o seu tema predileto ${ }^{20}$.

Diante desse cenário, podemos compreender o profissional de comunicação como um mediador cultural tal qual a acepção cunhada pelo antropólogo Gilberto Velho ${ }^{21}$. A partir da reflexão sobre as sociedades ocidentais modernas, heterogêneas e fragmentadas, o conceito de mediação cultural nos ajuda pensar esse elo entre realidades diferentes que se utilizam de códigos específicos. O mediador seria aquele capaz de estabelecer pontes e comunicação entre esses diferentes contextos ${ }^{21}$. Incluir nos currículos de comunicação social disciplinas que tratem transversalmente desses temas é um primeiro passo no sentido de contemplar essas realidades, atendendo ao disposto nas DCN.

\section{Procedimentos metodológicos}

As questões que nortearam o mapeamento realizado foram:

a) Qual é a oferta de disciplinas que integram os temas comunicação, saúde e ambiente nos cursos de graduação em comunicação social das IES brasileiras?

b) Quais interfaces entre esses três temas são mais frequentes nos currículos identificados (comunicação e saúde, saúde e ambiente, comunicação e ambiente)?

c) Que concepções de comunicação, saúde e ambiente foram identificadas nas ementas disponíveis a partir da busca online?

Para conhecer a oferta de disciplinas que avançam na integração entre saúde e ambiente em cursos de comunicação social, optamos por algumas estratégias de levantamento e sistematização de conteúdo, a saber:

1. Levantamento dos cursos de graduação presencial em comunicação social no Brasil: a partir do documento "Conceito Enade 2012" ${ }^{22}$ do Instituto Nacional de Estudos e Pesquisas Educacionais Anísio Teixeira (Inep), elaboramos a listagem de cursos de comunicação em funcionamento no país, sua distribuição geográfica, a natureza jurídica das IES ofertantes, bem como os conceitos atribuídos pelo Exame Nacional de Desempenho dos Estudantes (Enade).

2. Busca de grupos de pesquisa no diretório do Conselho Nacional de Desenvolvimento Científico e Tecnológico $(\mathrm{CNPq})^{23}$ : pela combinação de palavras-chave 'comunicação + saúde'; 'jornalismo ambiental'; e 'comunicação ambiental', pudemos identificar grupos de pesquisa que se dedicam a esses temas. A identificação das IES que abrigam estudos sistemáticos nessas áreas permitiu prosseguir com a pesquisa nos currículos dos cursos de graduação em comunicação social. Essa escolha foi orientada pela hipótese de que haveria maior possibilidade de identificarmos disciplinas com temas análogos ao que buscávamos (comunicação, saúde e ambiente) em IES com investimentos em pesquisas nesses mesmos temas. 
3. Levantamento das estruturas curriculares, ementas e/ou planos de curso: esse levantamento foi realizado, em primeiro lugar, de forma geral na ferramenta de busca Google ${ }^{24}$, e, depois, foi refinado com busca ativa no sítio eletrônico de cada uma das IES identificadas previamente na busca dos grupos de pesquisa. Inicialmente, procuramos identificar quais IES ofertavam cursos de graduação presencial em comunicação social, em quaisquer habilitações. Na sequência, buscamos as estruturas curriculares, ementas ou planos de curso, visando identificar a presença de disciplinas que tratavam dos temas-chave para essa pesquisa, admitindo diferentes combinações entre os temas comunicação, saúde e ambiente. Prosseguimos, então, com a busca das palavras-chave: 'saúde'; 'ambiente', 'ambiental', 'meio ambiente', 'científico' e 'científica'. Vale ressaltar que a escolha pelos dois últimos vocábulos decorreu do conhecimento prévio de que há cursos de comunicação que contemplam os temas de saúde e ambiente em disciplinas como jornalismo científico e divulgação científica.

4. Elaboração de uma matriz para análise do conteúdo das ementas identificadas a partir do levantamento realizado: de acordo com Bardin ${ }^{24}$, graças a alguns vestígios deixados em documentos, o analista pode descobrir dados e fenômenos do contexto que está a estudar. Inicialmente adotando como procedimento a identificação de temas, "a inferência é considerada uma operação lógica destinada a extrair conhecimentos sobre os aspectos latentes da mensagem analisada" ${ }^{25}$. Após a leitura das ementas e planos de curso disponíveis online, elegemos categorias que estruturaram uma matriz analítica dos conteúdos mais frequentemente abordados: comunicação; saúde; ambiente (e a variação ambiental); jornalismo; ética; sustentabilidade; cidadania; política.

\section{Resultados}

\section{Cursos de comunicação no Brasil}

A partir do levantamento dos resultados do Enade junto ao Inep ${ }^{22}$ foram localizados 610 cursos no total, entre os oferecidos por universidades, centros universitários e faculdades, conforme o quadro a seguir.

Quadro 1 - Cursos de comunicação social oferecidos por regiões no Brasil

\begin{tabular}{|l|c|c|}
\hline Região & $\begin{array}{c}\text { Total de cursos de } \\
\text { comunicação }\end{array}$ & IES (total) \\
\hline Norte & 25 & 17 \\
\hline Centro-Oeste & 61 & 38 \\
\hline Nordeste & 110 & 72 \\
\hline Sudeste & 302 & 172 \\
\hline Sul & 112 & 67 \\
\hline Total & 610 & 366 \\
\hline
\end{tabular}

Fonte: Elaborado pelas autoras com base no Enade22 2012. 
Além da distribuição geográfica, observamos como os cursos se distribuem segundo avaliação oficial, classificando os mesmos de acordo com os conceitos obtidos no Enade 2012 (Gráfico 1). Dos 610 cursos de comunicação do país, a maioria foi avaliada com conceito Enade 3. No Rio de Janeiro, por exemplo, nenhuma IES obteve conceitos de insuficiência (conceito 1) e de excelência (conceito 5), sendo a maioria avaliada com conceito 3 .

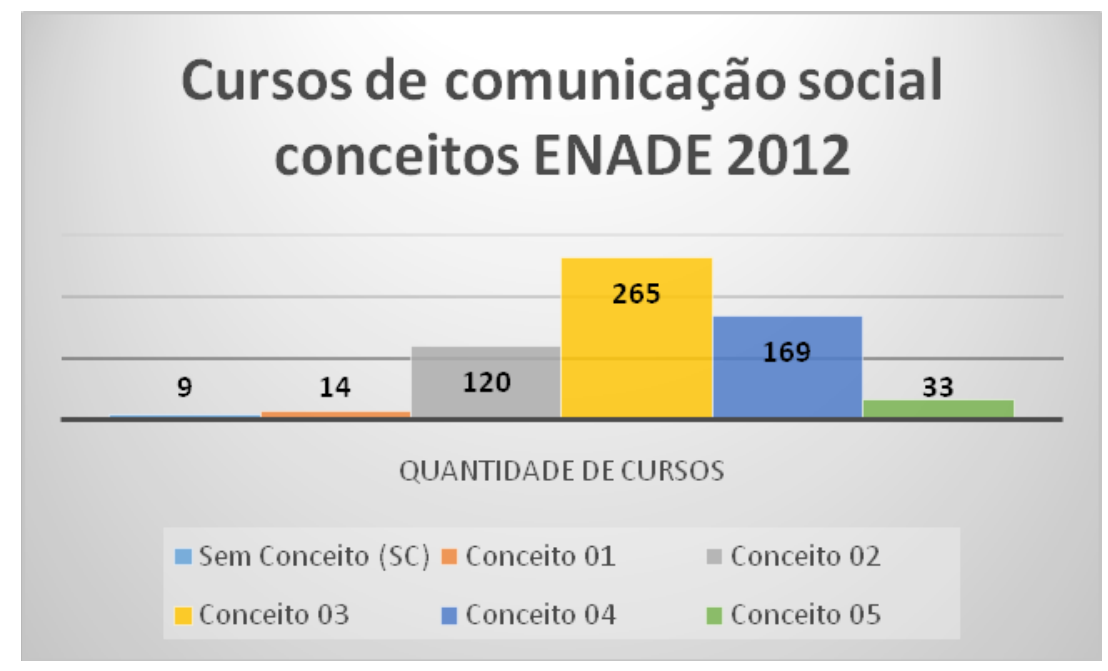

Gráfico 1 - Distribuição total dos cursos de comunicação social por conceito Fonte: Elaborado pelas autoras com base no Enade 222.

\section{Grupos de pesquisas cadastrados no CNPq}

Em nossa busca inicial, realizada no primeiro semestre de 2015, no diretório Grupo de Pesquisas do CNPq a partir do cruzamento dos termos-chave comunicação + saúde; comunicação + ambiental; jornalismo + ambiental; jornalismo + saúde, encontramos diversos grupos de pesquisa identificados com eles. A busca que mais propiciou resultados foi a de comunicação + saúde, em que se obteve a indicação de 110 grupos de pesquisa, sendo majoritariamente das ciências da saúde, mas apenas 20 estavam inseridos no campo que pretendemos estudar, o de ciências sociais aplicadas. Apesar disso, identificamos preliminarmente 28 grupos de pesquisas potenciais para o nosso estudo. Já as buscas com os termos comunicação + ambiental e jornalismo + ambiental, resultaram em um corpus menor, de 19 e 10 grupos de pesquisa, respectivamente, sendo ao menos um uma duplicação dos grupos já coletados. Por fim, as palavras-chave jornalismo + saúde levaram a apenas dois resultados.

\begin{tabular}{|l|c|c|c|c|c|c|}
\hline Palavras-chave & Total & Norte & Nordeste & Centro-Oeste & Sudeste & Sul \\
\hline Comunicação + saúde & $\mathbf{2 9}$ & 0 & 4 & 3 & 17 & 5 \\
\hline Comunicação + ambiental & $\mathbf{1 9}$ & 2 & 1 & 4 & 11 & 1 \\
\hline Jornalismo + ambiental & $\mathbf{1 0}$ & 2 & 3 & 2 & 1 & 2 \\
\hline
\end{tabular}

Quadro 2 - Busca de grupos de pesquisa: síntese por região

Fonte: Elaborado pelas autoras a partir do sítio eletrônico do CNPq pesquisado em 2015. 


\section{Disciplinas identificadas}

Após as buscas, foi possível localizar 38 disciplinas que de alguma forma contemplam os temas saúde e/ ou meio ambiente no universo da comunicação, segundo os critérios mencionados nos itens 2 e 3 da seção Procedimentos Metodológicos. Os títulos das disciplinas ora expressam uma aproximação mais direta com o campo do jornalismo, em denominações que apenas tangenciam as questões de saúde e meio ambiente como ocorre em 'jornalismo especializado’ e 'jornalismo científico', ora explicitam seu escopo como em 'jornalismo ambiental', 'comunicação e educação ambiental'; 'informação, comunicação e educação em saúde'; 'comunicação e saúde' e 'comunicação e meio ambiente'. Do total, 21 integram os currículos em caráter optativo ou complementar. A carga horária varia de 30 (seis ocorrências) a 120 horas (uma ocorrência). A maior parte das disciplinas com carga horária informada, porém, é ministrada em cursos de até 60 horas. Elas estão distribuídas pelas cinco regiões do país, mas há uma concentração maior no Sudeste (13 disciplinas). É interessante observar que na Região Norte, que concentra apenas $5 \%$ dos cursos de comunicação no país, foram identificadas sete disciplinas, das quais três tratam especificamente de jornalismo ambiental e uma de comunicação e sustentabilidade, sugerindo a relevância e a afinidade desses estudos com a vocação regional.

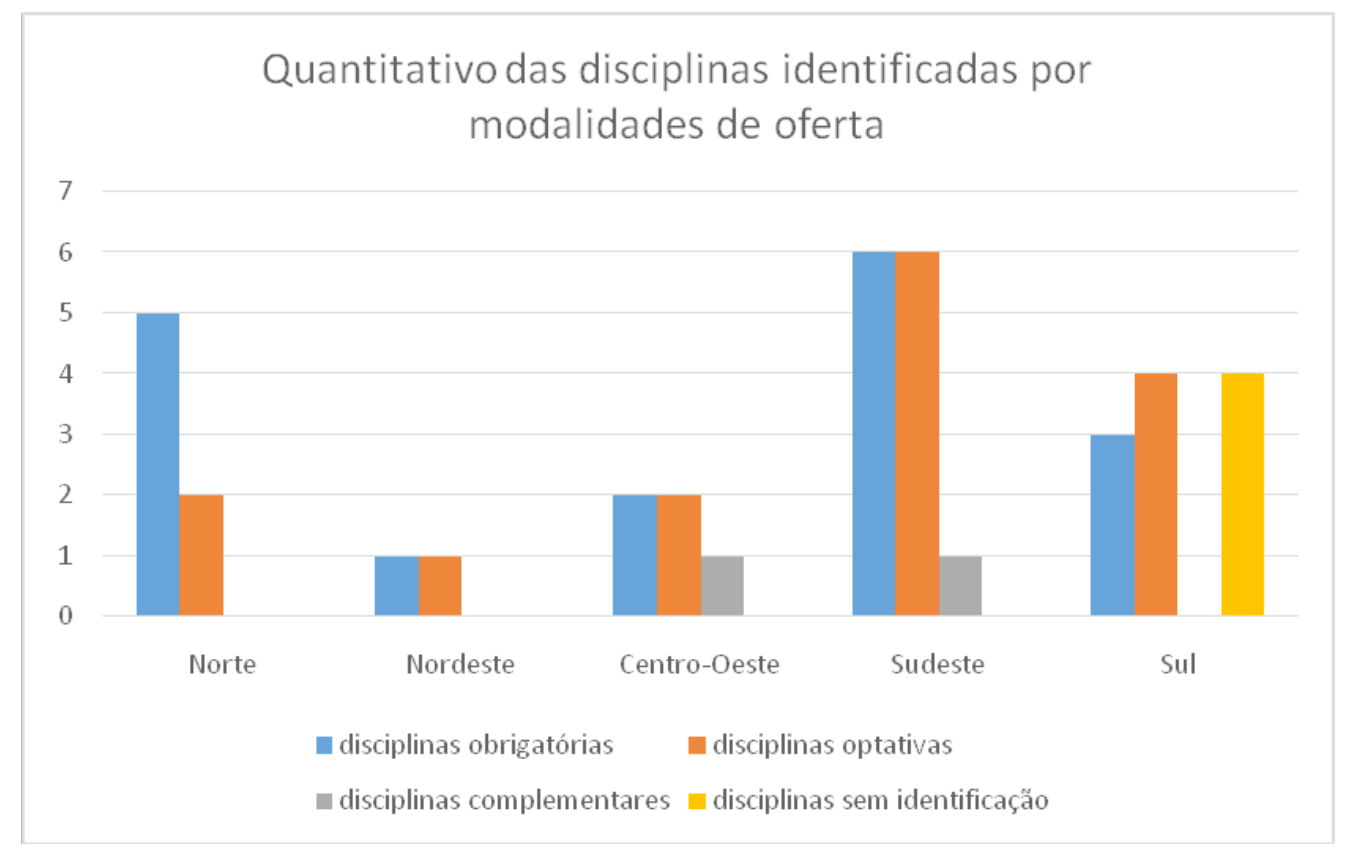

Gráfico 2 - Distribuição total das disciplinas identificadas por região

Fonte: Elaborado pelas autoras a partir dos sítios eletrônicos das IES 


\section{Comparação entre as disciplinas}

A fim de permitir uma comparação dos temas mais recorrentes nas disciplinas identificadas, empreendemos a análise de conteúdo a partir de uma matriz conceitual. Cabe destacar as limitações desse exercício em razão da baixa disponibilidade das ementas nas páginas virtuais dos cursos. Apenas 17 das 38 disciplinas, dispõem de uma descrição, ainda que breve, online. São elas:

a) Jornalismo ambiental, PUC-Rio;

b) Jornalismo ambiental, Ufap;

c) Jornalismo ambiental, UFV;

d) Jornalismo especializado: jornalismo e meio ambiente, UFSJ;

e) Jornalismo ambiental, UFPB;

f) Jornalismo ambiental, Ufop;

g) Informação, educação e comunicação em saúde, UNB;

h) Informação, educação e comunicação em saúde, UFPR;

i) Jornalismo ambiental, UniRitter;

j) Comunicação e meio ambiente, UFMT;

k) Educomunicação socioambiental, USP;

l) Jornalismo e saúde: a experiência brasileira, USP;

m) Jornalismo em agribusiness e meio ambiente no Brasil, USP;

n) Jornalismo científico, USP;

o) Jornalismo ambiental, UVI;

p) Jornalismo Científico, UVI;

q) Jornalismo Ambiental, UFRGS.

Quadro 3 - Matriz de análise temática das ementas disponíveis

\begin{tabular}{|l|c|c|c|c|c|c|c|c|c|c|c|c|c|c|c|c|c|c|}
\hline Categorias/Disciplinas & A & B & C & D & E & F & G & H & I & J & K & L & M & N & O & P & Q & Total \\
\hline Comunicação & & & X & & & X & X & X & & X & X & X & X & X & & & & 9 \\
\hline Saúde & & & & & & & X & X & & & & X & & & & & & 3 \\
\hline Ambiente & X & X & X & X & X & X & & & X & X & X & & & & X & & & 10 \\
\hline Jornalismo & X & X & X & X & X & X & & & X & & & X & X & X & X & X & & 12 \\
\hline Ética & X & X & & & & & & & & & & & & & & & & 2 \\
\hline Sustentabilidade & X & & & & & X & & & & & X & & & & & & X & 4 \\
\hline Cidadania & X & X & & & & & & & & & & & & & & & & 2 \\
\hline Política & & & & & X & & X & & & X & X & & & X & & & & 5 \\
\hline Total & $\mathbf{5}$ & $\mathbf{4}$ & $\mathbf{3}$ & $\mathbf{2}$ & $\mathbf{3}$ & $\mathbf{4}$ & $\mathbf{3}$ & $\mathbf{2}$ & $\mathbf{2}$ & $\mathbf{3}$ & $\mathbf{4}$ & $\mathbf{3}$ & $\mathbf{2}$ & $\mathbf{3}$ & $\mathbf{2}$ & $\mathbf{1}$ & $\mathbf{1}$ & \\
\hline
\end{tabular}

Fonte: Elaborado pelas autoras.

\section{Discussão}

Nos mais de 600 cursos da listagem do Enade/Inep ${ }^{22}$, identificamos apenas 38 disciplinas, sendo a maioria delas eletiva e concentradas no jornalismo ambiental, havendo duas que atuam na interface entre a comunicação e a saúde; uma que atua na interface entre comunicação e a educação ambiental e uma que se intitula comunicação (e não jornalismo) e meio ambiente. Não encontramos nenhuma correspondência entre os grupos de pesquisa e as disciplinas ofertadas. Mesmo quando identificamos grupos de pesquisa e disciplinas 
em uma mesma instituição, como a Universidade Federal do Paraná (UFRP), a Universidade do Vale do Itajaí (UVI) e a Universidade de São Paulo (USP), a temática abordada entre ambos não foi compatível.

A maioria das disciplinas de jornalismo ambiental prioriza conteúdos especializados, conforme constatamos pelas ementas e pelas referências bibliográficas sugeridas. As exceções ficam por conta dos planos de curso do Centro Universitário Ritter dos Reis (UniRitter) e da Pontífica Universidade Católica (PUC-Rio), e apenas no primeiro caso a disciplina é obrigatória. Embora a Universidade Federal da Paraíba (UFPB) aborde, na ementa, outros conceitos para além do jornalismo, na bibliografia apenas uma obra (a do jornalista André Trigueiro) avança na discussão. Se os conceitos gerais de ambiente são parcialmente aprofundados, a relação com a saúde é pouco ou nada problematizada, e não foi mencionada até então.

Uma iniciativa que se propõe a pensar na relação entre comunicação e ambiente de forma ampliada é a disciplina optativa da Universidade Federal do Mato Grosso (UFMT), cuja ementa privilegia a abordagem histórica entre comunicação e ambiente, problematiza práticas profissionais contemporâneas de divulgação científica, a responsabilidade socioambiental e o jornalismo ambiental. Não há, no entanto, menção a questões de saúde.

Na interface entre comunicação e saúde, identificamos a oferta de disciplinas optativas pela Universidade de Brasília (UNB) e pela Universidade Federal do Paraná (UFPR). A ementa completa da UNB encontravase disponível online, e as referências bibliográficas indicam a adoção de atitude problematizadora na análise da interface entre os campos da comunicação, informação, educação e saúde.

Entre as disciplinas de jornalismo ambiental, alguns autores se destacam nas bibliografias: Wilson da Costa Bueno; Ilza Girardi e Reges Schwaab; André Trigueiro; Sérgio Villas Boas. Na bibliografia de saúde, as referências são menos homogêneas. Wilson Bueno é também uma referência recorrente nas bibliografias das ementas analisadas, transitando pelo jornalismo científico em temas de saúde e ambiente.

De todas as disciplinas levantadas, a única que propõe integrar comunicação e educação ambiental é oferecida pela Universidade Federal do Rio Grande do Sul (UFRGS): a disciplina optativa chama-se "Comunicação e Educação Ambiental”, mas seu sítio eletrônico não disponibiliza ementa ou plano de curso, impedindo a análise de conteúdo da associação entre esses temas, que na prática profissional se entrecruzam frequentemente.

\section{Considerações finais}

Ao mapear a oferta de disciplinas que abordem comunicação, saúde e meio ambiente, identificamos que o ensino articulado desse trinômio não se verifica nas graduações de comunicação social, de acordo com os critérios que estabelecemos no item 4 da seção Procedimentos Metodológicos. Encontramos, no entanto, associações entre dois dos temas, especialmente as que reúnem saúde e meio ambiente. A quantidade de disciplinas encontradas com essa associação demonstra que ela já começa a ser abordada nos cursos de comunicação, ainda que de maneira incipiente: elas estão representadas em apenas $6 \%$ dos cursos, cabendo refletir sobre até que ponto os currículos de comunicação incorporam as necessidades sociais e do trabalho dos futuros comunicadores, seus egressos. Grande parte das disciplinas de jornalismo ambiental, mesmo as obrigatórias, foca principalmente nas características da área de especialização, em detrimento de uma visão mais global de conscientização ambiental.

Um aspecto que merece a atenção dos educadores responsáveis por esses cursos de graduação diz respeito à visibilidade da oferta dessas disciplinas: muitas das que foram localizadas não dispunham de ementa ou plano de curso, constando somente título e carga horária. Essa falta de informação foi observada especialmente entre as disciplinas que tratavam da temática de saúde, que não costuma ser imediatamente referenciada na grade curricular dos cursos. Essas disciplinas representam 13\% do total encontrado. 
Outra questão importante de ser destacada é o papel da Região Norte como capitalizadora da oferta de cursos voltados para as questões ambientais, cuja importância vem sendo crescentemente reconhecida pelos cursos de jornalismo em todo o país (ainda que sem explícitas imbricações com a saúde). Embora conte com menos de $5 \%$ dos cursos de comunicação no país, a região sedia a oferta de diversas disciplinas, inclusive obrigatórias, sobre os temas pesquisados.

O levantamento nos permitiu identificar ainda a desconexão entre os grupos de pesquisa e as disciplinas ofertadas, sugerindo um gap entre pesquisa e ensino nessas áreas. Ressalvamos, contudo, que esta hipótese necessita de estudos mais específicos para que seja confirmada ou refutada.

O presente levantamento enfrenta a dificuldade de basear-se em material disponível online, além de estar restrito aos cursos de graduação em comunicação social (e não no do ensino superior em geral). É possível pensar que uma IES pode contar com disciplina sobre saúde ou ambiente em outros departamentos e que os discentes de comunicação também sejam estimulados a cursá-las. Além disso, nossa premissa de um alinhamento de temas de pesquisa (dos grupos de pesquisa do CNPq) com o ensino de graduação não acrescentou dados que auxiliassem na identificação de iniciativas docentes. Estudos adicionais podem ser úteis para uma compreensão mais abrangente desse cenário relacionado aos currículos, lançando mão de outras fontes de informação.

\section{Referências}

1. Guimarães R, Souza IE, Santos IM. Ciência, tecnologia e pesquisa em saúde. In: Giovanella I et al. organizadoresPolíticas e sistema de saúde no Brasil. Rio de Janeiro: Fiocruz; 2012. p. 239-57.

2. Nascimento I. O autoconhecimento através dos números: as práticas de automonitoramento dos quantified selves [tese]. Doutorado em Comunicação e Cultura. Rio de Janeiro: Universidade Federal do Rio de Janeiro, 2014.

3. Zabalza M. O ensino universitário: seu cenário e seus protagonistas. São Paulo: Artmed; 2004. p. 19-66.

4. Lopes AC. Políticas de integração curricular. Rio de janeiro: Uerj; 2008.

5. Lopes FM. Jornalista por canudo: o diploma e o curso superior na construção da identidade jornalística [tese]. Doutorado em Comunicação e Cultura. Rio de Janeiro: Universidade Federal do Rio de Janeiro, 2012.

6. Brasil. Ministério da Educação. Secretaria de Educação Superior. Diretrizes Curriculares para os Cursos de Graduação Resolução CNE/CES n. 3, de 7 de novembro de 2001. [Internet].[citado em 18 maio 2016]. p.16, 23. Disponível em: http://www.mec.gov.br/sesu/diretriz.htm.

7. Freitas CM, Porto MF. Saúde, ambiente e sustentabilidade. Rio de Janeiro: Fiocruz; 2006. p. 31.

8. Bernardo CHC; Leão IB. Análise das matrizes curriculares dos cursos de comunicação social com habilitação em jornalismo no Brasil: um retrato da realidade nacional. Rev Bras Ciênc Comun [Internet] 2012 35(1):253-74. p. 273. Disponível em: http://repositorio.unesp.br/handle/11449/233

9. Lago AAC. Estocolmo, Rio de Janeiro e Joanesburgo: o Brasil e as três conferências ambientais das Nações Unidas. Brasília:Theasurus; 2006.

10. Almeida Filho N, Castiel, ID, Ayres, JR. Riesgo: concepto básico de la epidemiología. Salud Colect Internet]. Lanús, 2009 sept./dic. [citado em 03 nov. 2016]; 5(3):323-44. Disponível em: http://www. scielo.org.ar/scielo.php?script=sci arttext\&pid=S1851-82652009000300003.

11. Castiel, LD. Vivendo entre exposições e agravos: a teoria da relatividade do risco. História, ciências, saúde - Manguinhos 19963 (2): 237-264.

12. Minayo MCS. Saúde e ambiente: uma relação necessária. In: Campos, GWS et al. organizadores. Tratado de saúde coletiva. 2 ed. São Paulo: Hucitec, Rio de Janeiro: Fiocruz; 2009. p. 84, 90.

13. Ramos RR. Saúde ambiental: uma proposta interdisciplinar. Hygea - Rev Bras Geogr Med e da Saúde [Internet]. 2013 jun [citado em 03 nov. 2016]; 9(16):67-73. Disponível em: http://www.seer.ufu.br/ index.php/hygeia/article/view/21027/12454. 
14. Anais da 8a Conferência Nacional de Saúde. Brasília; 1986.

15. Bueno, WC. Jornalistas e pesquisadores: a parceria mais do que necessária. Portal do jornalismo científico [Internet]. Disponível em: http://www.jornalismocientifico.com.br/jornalismocientifico/artigos/ relacao jornalista cientista/artigo3.php

16. Organização Mundial da Saúde (OMS). Carta de Ottawa. Ottawa; 1986. Disponível em: http://bvsms. saude.gov.br/bvs/publicacoes/carta_ottawa.pdf

17. Organização Mundial da Saúde (OMS). Declaração de Alma-Ata. Alma-ata; 1978. Disponível em: http:// cmdss2011.org/site/wp-content/uploads/2011/07/declaração-alma-ata.pdf

18. Romeyer H, organizador. La santé dans l'espace public. Rennes: Presses de l'EHESP; 2010.

19. Lerner K. Doença, mídia e subjetividade: algumas aproximações teóricas. In: Lerner K, Sacramento,I, organizadores. Saúde e jornalismo: interfaces contemporâneas. Rio de Janeiro: Fiocruz; 2014.

20. Troiano. Estudo sobre o jornal O Globo. Rio de Janeiro; 2009. 15 slides, color.

21. Velho G, Kuschnir, K, organizadores. Mediação, cultura e política. Rio de Janeiro: Aeroplano; 2001.

22. Instituto Nacional de Estudos e Pesquisas Educacionais Anísio Teixeira. Resultados do Enade 2012 [Internet]. Brasília; 2012 . Disponível em: http://portal.inep.gov.br/enade/resultados

23. Conselho Nacional de Desenvolvimento Científico e Tecnológico - CNPq. Diretório dos Grupos de Pesquisa no Brasil - Lattes. Brasília; 2015. Disponível em: http://lattes.cnpq.br/web/dgp

24. Bardin, L. Análise de conteúdo. Lisboa: Edições 70; 2009.

25. Fonseca Júnior, WC. Análise de conteúdo. In: Duarte, J, Barros, A. Métodos e técnicas de pesquisa em comunicação. 2ed. São Paulo: Atlas; 2008. p. 280-304. p. 284. 